PROC. OF JSCE

No. 292, December 1979

\title{
BASIC STUDIES ON SCALE-UP OF SPIRAL FLOW AERATION TANKS
}

\author{
By Susumu HASHIMOTO* and Masanori FUJITA**
}

\section{SYNOPSIS}

The treatment of sewage and industrial wastes that makes use of a spiral type of flow aeration tank usually involves the following physical operations, viz., the supply of oxygen, mixing of liquid and the stripping of dissolved gaseous substances by bubbling through compressed air. Various types of air diffusion devices and diffuser location patterns have been developed to improve the efficiency of aeration ${ }^{1) \sim 1}$. Many studies on the optimum operational procedures of these devices are well documented. But very little information is known about the scale-up design procedure of aeration $\operatorname{tanks^{8)}}$. In bubble aeration systems, bubble rise only due to the difference between liquid density and bubble density. The supply of oxygen to the liquid, mixing of liquid and the circulation rate of liquid are all determined by the work of the bubbles rising through the liquid from the diffuser device to the surface of the liquid.

In this study, we attributed the bubble-work hypothesis to the over-all oxygen transfer coefficient and derived a scale-up equation for a spiral flow aeration tank using this over-all oxygen transfer coefficient.

\section{THEORY}

In the development of this theory, the following assumptions were made to simplify matters;

(1) The air bubble is an ideal sphere.

(2) Air bubbles are not structurally transformed, broken up or combined mutually.

The frictional force evident during the ascension of a single bubble is likely equal to the force im. bued in ascending bubbles. Thus, frictional force=ascending bubble force

* Professor, Dept. of Environmental Eng., Osaka University.

** Associate Professor, Dept. of Environmental Eng., Osaka University. where

$d=$ diameter of a bubble $(\mathrm{cm})$

$U=$ rising velocity of a bubble $(\mathrm{cm} / \mathrm{sec})$

$C_{D}=$ resistance coefficient

$\rho=$ liquid density $\left(\mathrm{g} / \mathrm{cm}^{3}\right)$

The work done by a single bubble ascending from the diffuser device to the surface of the liquid is given by the following equation.

$$
\left[W_{b}\right]_{s}=\frac{C_{D} \cdot \pi \cdot \rho \cdot U^{2} \cdot d^{2} \cdot\left(H-H_{0}\right)}{8 g_{c}} \cdots \cdots \cdots(
$$

where

$H=$ depth of water $(\mathrm{cm})$

$H_{0}=$ height of diffuser from the bottom (cm)

$g_{c}=$ conversion factor ( $\mathrm{g}-\mathrm{cm} / \mathrm{gr}-\mathrm{sec}^{2}$ )

$\left[W_{b}\right]_{s}=$ the "bubble-work" of a single bubble (g-cm)

The bubble-work, $W_{b}(\mathrm{~g}-\mathrm{cm} / \mathrm{sec})$ in the case of air flow rate of $G_{s}\left(\mathrm{~cm}^{3} / \mathrm{sec}\right)$ is

$$
W_{b}=\frac{3}{4} \cdot C_{D} \frac{\rho U^{2}}{g_{c}} \cdot \frac{H-H_{0}}{d} \cdot G_{s}
$$

In Eq. (3), $\left(H-H_{0}\right)$ represents a diffuser submergence. If the diffuser device is placed at the bottom, $H_{0}$ in Eq. (3) would be negligible. It is shown by Eq. (3) that the bubble-work depends on the diameter and rising velocity of bubbles, depth of water, diffuser submergence and air flow rates.

There are several studies on bubble rising velocity through the stagnant liquid by using various sizes of bubbles ${ }^{9) \sim 12)}$. Also we can find some studies on the behavior of either a single bubble in fluidized column or a group of bubbles in the bubble column ${ }^{13) \sim 15)}$. To relate a bubble diameter and rising velocity in fluidized column, Toei et $\mathrm{al}^{13}$ ) derived the following equation;

$$
U=0.98 \sqrt{g d}
$$

While Eq. (4) was derived for solid-gas system, the fluidized solid-gas mixture in a fluidized column sometimes may be assumed as a moving liquid like mixed liquor of activated sludge. Wallis, G.B. ${ }^{16)}$ classified the bubble rising velocity in the stagnant liquid in five regions depending on the bubble Reynolds number. According to Wallis' classifica- 
tion, the rising velocity for bubbles with diameter larger than $0.45 \mathrm{~cm}$ was assigned to region 4 and 5. In region 4 , the bubble rising velocity is independent on the bubble diameter. In region 5 , the bubble rising velocity depends on both accelaration of gravity and bubble diameter as follows;

$$
U \propto \sqrt{g d}
$$

Since it is reasonable to assume that the bubble diameter in a spiral flow aeration tank is in the ranges of more than $0.45 \mathrm{~cm}$, Eq. (5) can be used to describe its rising velocity. And for slightly smaller bubbles, Eq. (5) can be extrapolated to cover region 4 with little deviation. When we compare Eq. (4) with Eq. (5), it can be said that Eq. (5) approximates Eq. (4). It is consequently suggested by this approximation that Eq. (4) can be assumed as the equation for the bubble rising velocity in a spiral flow aeration tank. When Eq. (4) was substituted in Eq. (3), the following equation follows;

$$
W_{b}=0.72 C_{D} \cdot \rho \cdot\left(H-H_{0}\right) \cdot G_{s}
$$

Eq. (6) shows that the bubble-work is directly dependent on the diffuser submergence (or water depth) and air flow rate. Resistance coefficient, $C_{D}$ depends on the diameter and rising velocity of the bubble because of the function of Reynolds number $^{9), 10)}$.

Since the aeration tank used in this study was not transparent nor equipped with peepholes, both bubble diameter and bubble rising velocity could not be measured. We were then unable to determine an accurate $W_{b}$ in each experiment. In place thereof, we examined whether the theoretical horsepower requirement of a compressor could be used as a substitute for the bubble-work. The theoretical horsepower requirement of a compressor is given by the following equation ${ }^{17)}$;

$$
P=\left(\frac{r}{r-1}\right) p_{0} \cdot G_{s}\left[\left(\frac{p}{p_{0}}\right)^{\frac{r-1}{r}-1}\right]
$$

where

$P=$ theoretical horsepower requirement of a compressor $(\mathrm{g}-\mathrm{cm} / \mathrm{sec})$

$r=$ adiabatic compression coefficient $(r=1.4$ in air)

$p_{0}=$ pressure of the incoming air (atmospheric pressure $=1034 \mathrm{~g} / \mathrm{cm}^{2}$ )

$p=$ pressure of the compressed air emitted $\left(\mathrm{g} / \mathrm{cm}^{2}\right)$

The pressure of the air emitted is approximately described by ${ }^{17)}$;

$$
\left.\begin{array}{l}
p=p_{0}+1.25\left(H-H_{0}\right) \\
p=p_{0}+1.25 \mathrm{H}
\end{array}\right\}
$$

(if $H_{0}$ is negligible)

When Eq. (8) was substituted in Eq. (7), the following equation would be derived;

$$
P=\left(\frac{r}{r-1}\right) p_{0} \cdot G_{s}\left[\left\{1+\frac{1.25\left(H-H_{0}\right)}{p_{0}}\right\}^{\frac{r-1}{r}}-1\right]
$$

Since we usually use a spiral flow aeration tank whose water depth is less thah $5 \mathrm{~m}$, it can be assumed that ;

$$
\frac{1.25\left(H-H_{0}\right)}{p_{0}}<1
$$

Eq. (9) can be rewritten as follows;

$$
\begin{aligned}
P & \fallingdotseq \frac{r}{r-1} p_{0} \cdot G_{s}\left\{1+\frac{r-1}{r} \cdot \frac{1.25\left(H-H_{0}\right)}{p_{0}}-1\right\} \\
& \fallingdotseq 1.25\left(H-H_{0}\right) \cdot G_{s} \\
& \propto\left(H-H_{0}\right) \cdot G_{s} \cdots \cdots \ldots \ldots \ldots \ldots \ldots \ldots \ldots \ldots \cdot(10)
\end{aligned}
$$

Comparing Eq. (10) with Eq. (6), it can be seen that the theoretical horsepower requirement of a compressor, $P$, correlates well with the bubble-work, $W_{b}$. The relationship between $P$ and $W_{b}$ will be verified in the latter part of this study.

Dimension analysis of mass transfer shows ${ }^{18)}$;

$$
\mathrm{Sh}=c(\mathrm{Re})^{m}(\mathrm{Sc})^{n}
$$
where

$\mathrm{Sh}=$ Sherwood number $\left(=K_{L} d / D\right)$

$\mathrm{Re}=$ Reynolds number $(=d U / \nu)$

$\mathrm{Sc}=$ Schmidt number $(=\nu / D)$

$\nu=$ kinematic viscosity coefficient $\left(\mathrm{cm}^{2} / \mathrm{sec}\right)$

$D=$ diffusion coefficient $\left(\mathrm{cm}^{2} / \mathrm{sec}\right)$

Using Eq. (3), the above equation can be rearranged as follows ;

$$
K_{L} \frac{A}{V}=K_{L} a=c^{\prime} \frac{(d \cdot U)^{m-1}}{C_{D} U^{2}} \cdot \frac{W_{b}}{V}
$$

where $c^{\prime}=8 c D^{1-n} \nu^{n-m} g_{c^{\rho^{-1}}}$. Usually air flow rate is $1 \sim 2 \mathrm{~m}^{3}$ of air $/ \mathrm{m}^{3}$ of liquid/hr in a spiral flow aeration tank and much more in a bubble column. So we can consider that the hold up of a spiral flow aeration tank is quite small.

The interfacial area between liquid and bubbles per unit volume of liquid, $a$, is expressed by the following equation.

$$
a=\frac{A}{V}=\frac{6 G_{s}\left(H-H_{0}\right)}{d \cdot U \cdot V}
$$

In Eq. (11), Eckenfelder ${ }^{19,20)}$ represented the exponent, $m$, as a unit. If $m$ is assumed as a unit, Eq. (12) can be simplified as follows;

$$
K_{L} a=c^{\prime} \frac{1}{C_{D} \cdot U^{2}} \cdot \frac{W_{b}}{V}
$$

Combining Eq. (14) with Eq. (4), the following equation results ;

$$
K_{L} a=c^{\prime \prime} \frac{1}{C_{D} \cdot d} \cdot \frac{W_{b}}{V}
$$

where $c^{\prime \prime}=8 c D^{1-n} \nu^{n-1} \rho^{-1} g_{c} g^{-1}$.

Eq. (12) or (15) can be used as the scale-up equation of a spiral flow aeration tank which is equipped with a diffusion device that could release bubbles of uniform determinable diameter.

\section{MATERIALS AND METHODS}

The aeration tanks used in this study are shown in Fig. 1, Fig. 2 and Fig. 3. 
(1) Cylindrical experimental aeration tank: This is a $14 \mathrm{~cm}$ diameter $\times 40 \mathrm{~cm}$ height tank. Working volume is $4.5 \mathrm{l}$. and water depth is $30 \mathrm{~cm}$. Aeration was performed by a porous diffuser. Air flow rate was $0.5 \mathrm{l} / \mathrm{min}, 1.5 \mathrm{l} / \mathrm{min}$ or $3.0 \mathrm{l} / \mathrm{min}$, and $K_{L} a$ was computed by the moment method $^{21)}$. Dissolved oxygen (DO) concentration was measured by a DO meter (see Fig. 1).

(2) Cubical experimental aeration tank: This is a $47 \mathrm{~cm}$ long $\times 47 \mathrm{~cm}$ wide $\times 74 \mathrm{~cm}$ high tank and its capacity is $100 l$. Water depth is $47 \mathrm{~cm}$. Aeration device was a porous plate diffuser placed at the wall of the tank bottom. Air flow rate varied from $5 l / \mathrm{min}$ to $30 l / \mathrm{min}$. $K_{L} a$ was computed by the moment method and DO concentration was measured by a DO meter (see Fig. 2).

(3) Pilot scale aeration tank: This tank is $50 \mathrm{~cm}$ long $\times 287 \mathrm{~cm}$ wide $\times 200 \mathrm{~cm}$ high with a capacity of $2.68 \mathrm{~m}^{3}$. And its water depth is $187 \mathrm{~cm}$. Sparger and plastic plate diffuser were used as diffuser devices and were placed either at the center of the tank or at the wall of the tank. Diffuser submergences were varied in each experiment. Sparger's submergences were $48 \mathrm{~cm}, 93 \mathrm{~cm}, 137 \mathrm{~cm}$ and $173 \mathrm{~cm}$ reckoned from the surface of the water for both diffuser locations i.e., at the center and at the wall.

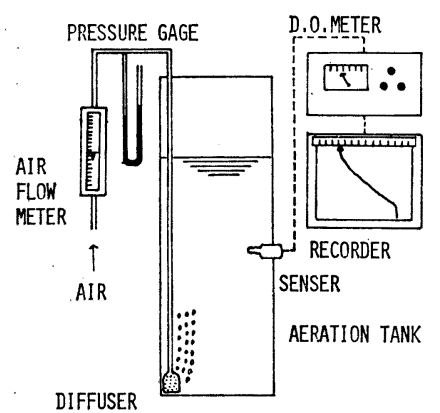

Fig. 1 Schematic diagram of a cylindrical experimental aeration tank (Working volume is $4.5 l$ and water depth is $30 \mathrm{~cm}$ ).

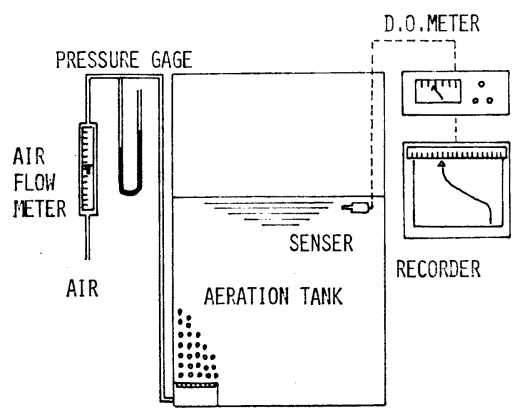

PLATE DIFFUSER

Fig. 2 Schematic diagram of a cubical experimental aeration tank (Working volume is $100 l$ and water depth is $47 \mathrm{~cm}$ ).
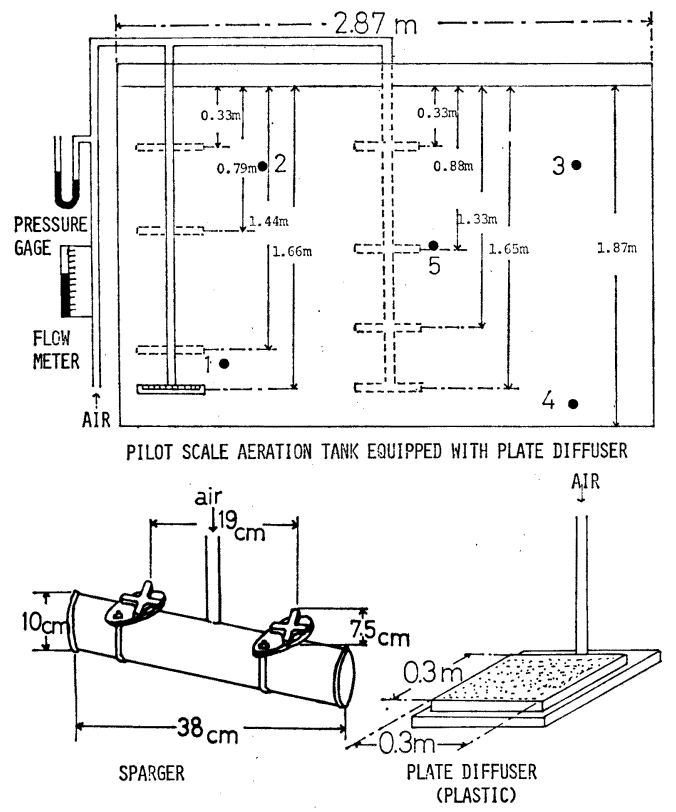

Fig. 3 Schematic diagrams of a pilot scale aeration tank and diffusion devices (Number 1 to 5 is the sampling position, working volume is $2.68 \mathrm{~m}^{8}$ and water depth is $1.87 \mathrm{~m}$ ).

The plate diffuser's submergences are shown in Fig. 3. The air flow rate varied from $3 \mathrm{~m}^{3} / \mathrm{hr}$ to $11 \mathrm{~m}^{3} / \mathrm{hr}$, and $K_{L} a$ was computed by the moment method. DO concentration was measured by the Winkler's method ${ }^{22)}$.

Tap water was used in all experiments and $K_{L} a$ at the room temperature was converted to $K_{L} a$ of $20^{\circ} \mathrm{C}$.

\section{RESULTS AND DISCUSSIONS}

(1) Relationship between bubble-work or the theoretical horsepower requirement and $K_{L} a$ in various spiral flow aeration tanks.

Using the pilot scale aeration tank in Fig. 3, the bubble-work, $W_{b}$, calculated by Eq. (6) was compared with the theoretical horsepower requirement of a compressor calculated by Eq. (7). When we calculated the bubble-work, $W_{b}$, we assumed that the diameter of a bubble was $0.45 \mathrm{~cm}$ in spite of air flow rate and the bubble rising velocity was 28 ; $\mathrm{cm} / \mathrm{sec}$ as reported by Kashiwaya et $\mathrm{al}^{23)}$, who measured the bubble diameter and the bubble rising ! velocity by using a ceramic plate diffuser in a pilot scale aeration tank. The value of $\mathrm{Re} \cdot \mathrm{M}^{0.23}$ was first calculated as described by Harberman $\cdot$ Morton $^{9}$. And then, using the relationship between $\operatorname{Re} \cdot \mathrm{M}^{0.23}$ and the resistance coefficient, $C_{D}$ shown by Tadaki 
Maeda ${ }^{10)}$, the resistance coefficient was estimated and the bubble-work, $W_{b}$ was calculated. The pressure of the compressed air emitted, $p$, was measured directly and the theoretical horsepower requirement of a compressor, $P$, was evaluated. The relationship between $W_{b}$ and $P$ is shown in Fig. 4. This was done purportedly to circumvent the difficulty of directly measuring the diameters and rising velocities of the bubbles, from which we were to calculate the bubble-work. We used instead the theoretical horsepower requirement of a compressor, $P$, as a substitute for $W_{b}$ in as much as we have theoretically and experimentally shown that they were well intercorrelated.

The relationship between $K_{L} a$ and $P / V$ using various experimental aeration tanks (Fig. 1,2 and 3 ) is shown in Fig. 5. In Fig. 5, the correlation lines between $K_{L} a$ and $P / V$ derived by Teraoka et $\mathrm{al}^{24)}$, Morgan.Bewtra ${ }^{3)}$ and King ${ }^{1)}$ are simultaneously shown. Table 1 shows tank dimensions and kinds of diffusers presented in Fig. 5.

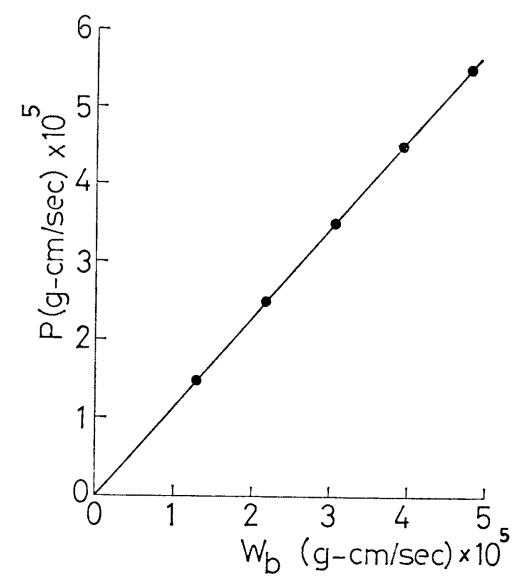

Fig. 4 Relationship between the bubble-work, $W_{b}$ and the theoretical horsepower requirement of a compressor, $P$ (Calculated for a pilot scale aeration tank shown in Fig. 3).
The slopes of all lines in Fig. 5 are nearly equal to 0.8 . This empirical finding suggested that Eq. (15) might be applicable to various scales of aeration tanks. The reason why these slopes are less than one is believed to be due to the increase of bubble diameter as the air flow rate is increased, such increase which consequently promoted the profuse coalescence of bubbles ${ }^{2)}$.

From a practical point of view, we plotted the $K_{L} a$ value at $P / V=1\left(\mathrm{~kg}-\mathrm{m} / \mathrm{m}^{3}\right.$-sec $)$ against water depth. We thus obtained Fig. 6 to explain the two types of linear lines. King's data made up one line and Teraoka et al's and Morgan-Bewtra's date composed the other line with our data. These two lines vary due to the different bubble sizes produced by

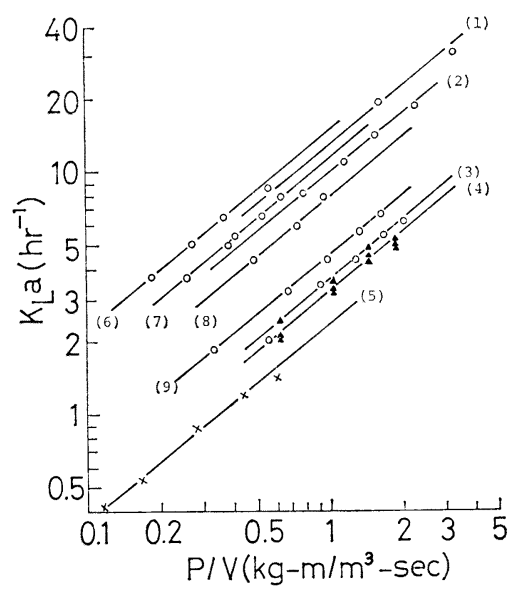

(1) authors' result, $H=0.30 \mathrm{~m}, V=4.5 \mathrm{l}$

(2) authors' result, $H=0.47 \mathrm{~m}, V=100 l$

(3) authors' result, $H=1.87 \mathrm{~m}, V=2.68 \mathrm{~m}^{3}$

(4) Teraoka et $\mathrm{al}^{24)}, H=3.00 \mathrm{~m}, V=36 \mathrm{~m}^{3}$

(5) Morgan, P.F., Bewtra, J.K. ${ }^{8}, H=4.57 \mathrm{~m}, V=40.78 \mathrm{~m}^{8}$

(6) King, H.R. ${ }^{1)} H=0.28 \mathrm{~m}, V=40 l$

(7) King, H.R. ${ }^{1)} H=0.53 \mathrm{~m}, V=150 l$

(8) King, H.R. ${ }^{1)} H=1.0 \mathrm{~m}, V=950 l$

(9) King, H.R. ${ }^{1)} H=4.57 \mathrm{~m}$, Industrial scale

Fig. 5 Relationship between the over-all oxygen transfer coefficient and the theoretical horsepower requirement of a compressor.

Table 1 Description of tank shape and dimension and diffusers employed by other investigators which were utilized in Fig. 5 for comparative purposes.

\begin{tabular}{|c|c|c|c|c|c|}
\hline & Reference & Tank Dimensions & $\begin{array}{c}\text { Water Depth } \\
H(\mathrm{~m})\end{array}$ & $\begin{array}{c}\text { Tank Volume } \\
V\left(\mathrm{~m}^{3}\right)\end{array}$ & Diffuser \\
\hline (1) & Authors & $14 \mathrm{~cm} \times 40 \mathrm{~cm}$ & 0.30 & 0.0045 & Porous Stone \\
\hline (2) & Authors & $47 \mathrm{~cm} \times 47 \mathrm{~cm} \times 74 \mathrm{~cm}$ & 0.47 & 0.100 & Ceramic Plate \\
\hline (3) & Authors & $50 \mathrm{~cm} \times 287 \mathrm{~cm} \times 200 \mathrm{~cm}$ & 1.87 & 2.68 & Plastic Plate \\
\hline (4) & Teraoka et $\mathrm{al}^{24)}$ & Pilot Scale & 3.00 & 36 & Plastic Tube \\
\hline (5) & Morgan Bewtra ${ }^{3)}$ & $7.3 \mathrm{~m} \times 1.2 \mathrm{~m} \times 5.0 \mathrm{~m}$ & 4.57 & 40.78 & Saran Tube \\
\hline (6) & King ${ }^{1)}$ & $25.4 \mathrm{~cm} \times 55.9 \mathrm{~cm} \times 33.0 \mathrm{~cm}$ & 0.28 & 0.040 & Ceramic Plate \\
\hline$(7)$ & King $^{1)}$ & $25.4 \mathrm{~cm} \times 111.8 \mathrm{~cm} \times 58.4 \mathrm{~cm}$ & 0.53 & 0.150 & Ceramic Plate \\
\hline$(8)$ & King ${ }^{1)}$ & $48.3 \mathrm{~cm} \times 198.1 \mathrm{~cm} \times 104.7 \mathrm{~cm}$ & 1.00 & 0.950 & Ceramic Plate \\
\hline (9) & King ${ }^{1)}$ & Industrial Scale & 4.57 & & Ceramic Plate \\
\hline
\end{tabular}




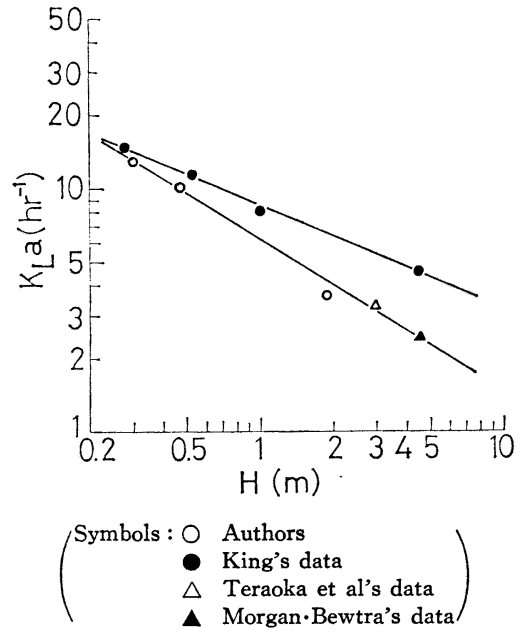

Fig. 6 Effect of water depth on the over-all oxygen transfer coefficient.

different diffusers. From Fig. 5 and Fig. 6, we can get the following equation. Our data containing Teraoka et al's and Morgan-Bewtra's data would result to:

$$
K_{L} a=5.9(P / V)^{4 / 5}(H)^{-2 / 3}
$$

while King'data would be :

$$
K_{L} a=8.6(P / V)^{4 / 5}(H)^{-2 / 5}
$$

where $P / V$ is $\mathrm{kg}-\mathrm{m} / \mathrm{m}^{3}$-sec, and $H$ is $\mathrm{m}$.

Exponents and constants in Eq. (16) and (17) are influenced by the dimensions and geometrical shapes of the aeration tanks and diffusion devices. It has been shown that oxygen transfer efficiencies from the water surface decreases with the increase of water depth, so this is considered to be one of the reasons why the exponent of $H$ carries a negative sign. But we will investigate this problem further.

In the scale-up of a spiral flow aeration tank, we have to determine the theoretical horsepower requirement of a compressor to maintain the same $\left(K_{L} a\right)_{L}$ in a practical tank as $\left(K_{L} a\right)_{S}$ in a bench or pilot scale tank. But sometimes it is difficult to measure the $\left(K_{L} a\right)_{S}$ in a bench or pilot scale aeration tank during the treatment of wastewater. In this case, we have to use the following equation derived from Eq. (16) ;

$$
\left(\frac{P}{V}\right)_{L}=\left(\frac{H_{L}}{H_{S}}\right)^{5 / 6}\left(\frac{P}{V}\right)_{S}
$$

where subscript $L$ represents a large tank and subscript $S$ is for a small tank. If we derive an equation from Eq. (17) in the same way, the exponent of $\left(H_{L} / H_{S}\right)$ in Eq. (18) becomes $1 / 2$. Since the water depth used in Fig. 5 ranged from $0.3 \mathrm{~m}$ to $4.6 \mathrm{~m}$, Eq. (16), (17) or (18) would be applicable to the ordinary spiral flow aeration tank. We can thus predict the theoretical horsepower requirement of a spiral flow aeration tank by using either Eq. (16) (or Eq. (17)) or Eq. (18) if we can get either the optimal $K_{L} a$ or the optimal horsepower requirement during the treatment of wastewater in a bench or pilot scale aeration tank.

\section{(2) Effects of diffuser submergences and diffuser locations on scale-up of spiral flow aeration tank.}

If diffusers are hung at the middle point of the tank from the surface of the water, the system requires less horsepower for compressing air as compared with the other conventional processes, one of which is called Inka system ${ }^{25), 26)}$.

In this studies, we set up the diffuser both at the wall and at the center of the aeration tank, and varied the diffuser submergence at each diffuser location. We determined the relationship between $K_{L} a$ and the bubble-work or theoretical horsepower requirement in each case of aeration system. In this experiment, we used a pilot scale aeration tank and adopted a sparger and a plate diffuser as a diffusion device as shown in Fig. 3. The Eq. (3) shows that the bubble-work, $W_{b}$, is in proportion to the diffuser submergence, $\left(H-H_{0}\right)$. It was then assumed that $K_{L} a$ in each case of aeration system was correlated to the bubble-work or the theoretical horsepower requirement of a compressor. As it has been mentioned above, the theoretical horsepower, $P$, could be used as a substitute for the bubble-work, $W_{b}$. Hence, we plotted $K_{L} a$ values against $P / V$ calculated from Eq. (7). This result is shown in Fig. 7. This figure shows two linear correlation lines in spite of the different diffuser submergences and locations. The data from the sparger represent one line and the data obtained from the plate diffuser represent the other line. This is due to the difference of the bubble diameter between the sparger

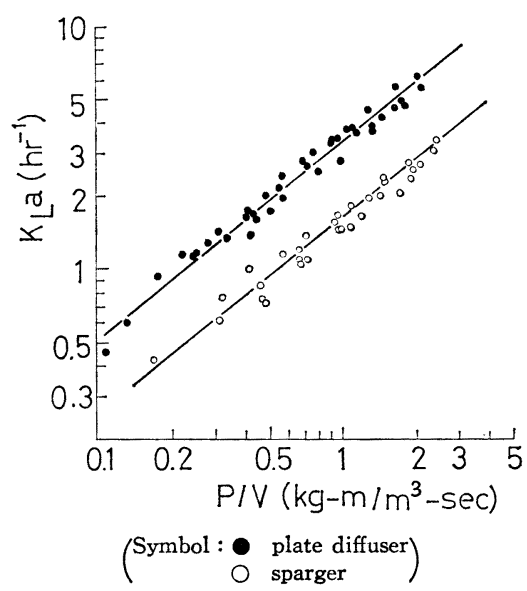

Fig. 7 Relationship between $K_{L} a$ and $P / V$ in a pilot scale aeration tank under a variable diffuser submergence and diffuser location. 
and the plate diffuser. The following equations are derived from Fig. 7;

The plate diffuser:

$$
K_{L} a=3.3(P / V)^{4 / 5}
$$

The sparger :

$$
K_{L} a=1.6(P / V)^{4 / 5}
$$

The plate diffuser achieved higher oxygen transfer efficiency gauged against the theoretical horsepower as compared with that of the sparger.

The slopes of the two lines in Fig. 7 are equal to 0.8 which is similar to the result of Fig. 5 . According to Eq. (15), the slopes of the lines should equal to 1 . The difference is probably due to the ideal conditions assumed for developing Eq. (15). But in this study, we are trying to apply the idea of bubble-work theory to the scale-up of a spiral flow aeration tank. Fig. 7 suggests basically that Eq. (3) and Eq. (6) can be successfully applied to the spiral flow aeration tank even if we vary the depth of diffuser submergence and the diffuser location. In summary, using the bubble-work or the theoretical horsepower requirement of a compressor for practical reason, we can actually scale-up spiral flow aeration tanks for as long as they equipped with a diffusion device which could release bubbles of uniform diameter not withstanding variances in diffuser submergence position, the diffuser location and the water depth.

\section{ABSTRACT}

(1) We attributed the bubble-work to the overall oxygen transfer coefficient and derived the scaleup equation of a spiral flow aeration tank by using this over-all oxygen transfer coefficient. It was shown theoretically and experimentally that the theoretical horsepower requirement of a compressor, $P$, could be used as a substitute for the bubblework, $W_{b}$. By using different scales of aeration tanks, we could correlate the $K_{L} a$ value to $P / V$ and verify the presented scale-up theory.

(2) We could obtain a good correlation equation between $K_{L} a, P / V$ and water depth, $H$, by using various spiral flow aeration tanks which were equipped with diffusion devices releasing bubbles of uniform diameter.

(3) In spite of the diffuser submergence and location of the pilot scale spiral flow aeration tank, a linear relationship between $K_{L} a$ and $P / V$ was obtained. It is plausible to infer then that the scale-up of the spiral flow aeration tank could be adopted per se in wastewater treatment processes for as long as the release bubbles would be diametrically uniform.

\section{NOMENCLATURE}

$U=$ bubble rising velocity $(\mathrm{cm} / \mathrm{sec})$

$$
\begin{aligned}
d & =\text { bubble diameter }(\mathrm{cm}) \\
\rho & =\text { liquid density }\left(\mathrm{g} / \mathrm{cm}^{3}\right) \\
H & =\text { water depth }(\mathrm{cm}) \\
H_{0} & =\text { diffuser height from the bottom }(\mathrm{cm}) \\
h & =\text { diffuser submergence }(\mathrm{cm})=H-H_{0} \\
G_{s} & =\text { air flow rate }\left(\mathrm{cm}^{3} / \mathrm{sec}\right) \\
W_{b} & =\text { works by rising bubbles }\left(\mathrm{g}-\mathrm{cm}^{\prime} / \mathrm{sec}\right) \\
& =\text { bubble-work }
\end{aligned}
$$

$\left[W_{b}\right]_{s}=$ work by a single rising bubble $(\mathrm{g}-\mathrm{cm})$

$g_{c}=$ conversion factor $\left(\mathrm{g}-\mathrm{cm} / \mathrm{gr}-\mathrm{sec}^{2}\right)$

$C_{D}=$ resistance coefficient

$g=$ acceleration of gravity $\left(\mathrm{cm} / \mathrm{sec}^{2}\right)$

$\mathrm{Sh}=$ Sherwood number $\left(K_{L} \cdot d / D\right)$

$\mathrm{Re}=$ Reynolds number $(d \cdot U / \nu)$

$\mathrm{Sc}=$ Schmidt number $(\nu / D)$

$\nu=$ kinematic viscosity coefficient $\left(\mathrm{cm}^{2} / \mathrm{sec}\right)$

$D=$ diffusion coefficient $\left(\mathrm{cm}^{2} / \mathrm{sec}\right)$

$r=$ adiabatic compression coefficient $(r=1.4$ in air)

$A=$ surface area of bubbles $\left(\mathrm{cm}^{2}\right)$

$V=$ tank volume $\left(\mathrm{cm}^{3}\right)$

$P=$ theoretical horsepower requirement of a compressor (g-cm/sec)

$p=$ pressure of the compressed air emitted $\left(\mathrm{g} / \mathrm{cm}^{2}\right)$

$p_{0}=$ pressure of the incoming air (atmospheric pressure $=1034 \mathrm{~g} / \mathrm{cm}^{2}$ )

$c, c^{\prime}, c^{\prime \prime}=$ constant

$m, n=$ exponent

\section{ACKNOWLEDGEMENT}

The authors want to express their gratitude to Profs. K. Ichikawa, H. Taguchi and S. Aiba of Osaka University for the suggestions and discussions during elaboration of this work.

This work was supported in part by a Grant-inaid for Scientific Research, 1976 from the Ministry of Education, Japan.

\section{REFERENCES}

1) King, H.R. : Mechanics of oxygen absorption in spiral flow aeration tanks I., II., III., Sew. \& Ind. Wastes, Vol. 27, pp. 894 908, pp. 1007 1026, pp. 1123 1129, 1955.

2) Hashimoto, S., T. Shimazaki and H. Shirashoji : Studies on aeration performance of spiral flow aeration tank with porous plate diffuser as applied to sewage treatment, Jour. of Fermentation Technology, Vol. 41, No. 4, pp. 208 227, 1963.

3) Morgan, P.F. and J.K. Bewtra : Air diffuser efficiencies, Jour. Water Poll. Control Fed., Vol. 32, pp. 1047 1059, 1960.

4) Hashimoto, S. : Studies on oxygen transfer characteristics of diffused aeration devices in sewage treatment, Jour. of Fermentation Technology, Vol. 44, No. 10, pp. 699 710, 1966. 
5) Bewtra, J.K. and W.R. Nicholas : Oxygenation from diffused air in aeration tanks, Jour. Water Poll. Control Fed. Vol. 36, No. 10, pp. 1195 1224, 1964.

6) Leary, R.D., L.A. Ernest and W.J. Katz : Full scale oxygen transfer studies of seven diffuser systems, Jour. Water Poll. Control Fed., Vol. 41, No. 3, pp. 459 473, 1969.

7) Aberley, R.C., G.B. Rattray and P.P. Dougas : Air diffusion unit, Jour. Water Poll. Control Fed., Vol. 46, No. 5, pp. 896 910, 1974.

8) Aiba, S., A.E. Humphrey and N.F. Millis: Biochemical Engineering, 2nd Edition, University of Tokyo Press, Tokyo, 1973.

9) Haberman, W.L. and R.K. Morton : An experimental study of bubbles moving in liquids, Proc. ASCE, Eng. Mechanics Div., Vol. 80, No. 387, January, 1954.

10) Tadaki, T. and S. Maeda : On the shape and velocity of single air bubbles rising in various liquids, Kagaku Kogaku (Chem. Eng'g., Japan), Vol. 25, No. 4, pp. 254 264, 1961.

11) Kubota, M., T. Akehata and T. Shirai : The behavior of single air bubbles in low-viscosity liquids, Kagaku Kogaku (Chem. Eng'g., Japan), Vol. 31, No. 11, pp. 1074 1080, 1967.

12) Matsumoto, J. and M. Nakamura : Fundamental studies on the air bubbles from a single orifice-Distribution of the sizes of the air bubbles and the rate of oxygen transfer, Jour. of Civil Eng'g. of Japan, No. 173 (3), pp. 49 57, 1970.

13) Toei, R., R. Matsuno, H. Kojima, Y. Nagai, K. Nakagawa and S. Yu : Behaviors of bubbles in gassolid fluidized bed, Kagaku Kogaku (Chem. Eng'g., Japan), Vol. 29, No. 11, pp. 851 857, 1965.

14) Hiraki, I. and D. Kunii : Behavior of bubbles in fluidized beds, Kagaku Kogaku (Chem. Eng'g., Japan), Vol. 33, No. 7, pp. 680 684, 1969.

15) Koide, K., T. Hirahara and H. Kubota : Average bubble diameter, slip velocity and gas holdup of bubble swarms, Kagaku Kogaku (Chem. Eng'g., Japan), Vol. 30, No. 8, pp. 712 718, 1966.

16) Wallis, G.B. : One-dimensional two-phase flow, Mc Graw Hill, Inc., New York, 1969.

17) Fair, G.M. and J.C. Geyer : Water Supply \& Wastewater Disposal, John Wiley \& Sons, Inc., New York, 1954.

18) Fujita, S. : Kagaku Kogaku I, Iwanami Zensho 216, Tokyo, 1956.

19) Eckenfelder, W.W., Jr. and D.J. O'Conner : Biological Waste Treatment, Pergamon Press, Oxford, London, New York, Paris, 1961.

20) Eckenfelder, W.W., Jr. : Absorption of oxygen from air bubbles in water, Proc. ASCE, Jour. SA Div., Vol. 85, No. SA 4, pp. 89 99, 1959.

21) Fujita, M. and S. Hashimoto : Studies on computation and application of over-all oxygen transfer coefficient of aeration tank, Jour. of Fermentation Technology, Vol. 48, No. 8, pp. 461 469, 1970.

22) Standard Methods for the Examination of Water and Wastewater, 13th Ed., Amer. Pub. Health Assn., AWWA and WPCF, New York, 1971.

23) Kashiwaya, M., T. Yasunaka and N. Oikawa : Oxygen Transfer in Diffused Aeration Tank., 7th Sanitary Engineering Research Conference Abstracts, pp. 91 100, 1971.

24) Teraoka, H., K. Shimizu, K. Asano, M. Fukunaga, and K. Kubota: Basic study on diffusion devices, Report of Suido Kenkusho (Kubota Iron Ind., Ltd.), Vol. 5, No. 1, pp. 12 18, 1968.

25) Suschka, J. : Oxygenation in aeration tanks, Jour. Water Poll. Control Fed., Vol. 43, No. 1, pp. 81 92, 1971.

26) Fischerstrom, C.H. : Low pressure aeration of water and sewage, Proc. ASCE, Jour. SA Div., Vol. 86, No. SA 5, pp. 21 56, 1960.

(Recieved June 29, 1978) 